\title{
Berberine Attenuated Aging-Accelerating Effect of High Temperature in Drosophila Model
}

\author{
Valeriya Navrotskaya ${ }^{1}$, Gregory Oxenkrug ${ }^{2 *}$, Lyudmila Vorobyova ${ }^{1}$, Paul Summergrad ${ }^{2}$ \\ ${ }^{1}$ V. N. Karazin Kharkiv National University, Kharkiv, Ukraine; ${ }^{2}$ Tufts University School of Medicine, Tufts Medical Center, Boston, \\ USA. \\ Email: "goxenkrug@tuftsmedicalcenter.org
}

Received November $25^{\text {th }}, 2013$; revised December $26^{\text {th }}, 2013$; accepted January $15^{\text {th }}, 2014$

Copyright (C) 2014 Valeriya Navrotskaya et al. This is an open access article distributed under the Creative Commons Attribution License, which permits unrestricted use, distribution, and reproduction in any medium, provided the original work is properly cited. In accordance of the Creative Commons Attribution License all Copyrights (C) 2014 are reserved for SCIRP and the owner of the intellectual property Valeriya Navrotskaya et al. All Copyright (C) 2014 are guarded by law and by SCIRP as a guardian.

\section{ABSTRACT}

We have observed that berberine prolonged life span and improved viability of pupae and climbing activity of imagoes of wild-type Drosophila melanogaster maintained at $23^{\circ} \mathrm{C}$. As a continuation of our studies of berberine effect on life span, we were interested to evaluate the effect of berberine of life span in flies maintained at a higher temperature $\left(28^{\circ} \mathrm{C}\right)$ known to accelerate aging in wild type flies. Considering that genetically or pharmacologically induced deficiency of TRP conversion into KYN prolonged life span in a Drosophila model, we compared the effects of berberine, a powerful inhibitor of kynurenine (KYN) formation from tryptophan (TRP), on life span in wild type and in Drosophila melanogaster mutants (vermilion) with deficient TRP-KYN metabolism maintained at $23^{\circ} \mathrm{C}$ and $28^{\circ} \mathrm{C}$. High $\left(28^{\circ} \mathrm{C}\right)$ ambient temperature decreased life span in both wild type and vermilion flies. Aging accelerating effect of high temperature was more pronounced in Oregon than in vermilion flies $(-60 \%$ vs. $-\mathbf{4 0} \%$ decrease of mean life span, resp). Berberine attenuated the aging-accelerating effect of high temperature. Effect of berberine was more pronounced in Oregon $(+46 \%)$ than in vermilion (+22\%) flies. The obtained data suggested the possible involvement of TRP-KYN metabolism in the aging-acceleration effect of the high temperature and in protective effect of berberine.

\section{KEYWORDS}

Berberine; Life Span; Drosophila Melanogaster; High Temperature; Kynurenine

\section{Introduction}

Up-regulation of kynurenine (KYN) pathway of tryptophan (TRP) metabolism was suggested as one of the mechanisms of neurodegenerative disorders of aging [1-3]. We found that Drosophila melanogaster mutants with deficient formation of KYN, vermilion and white, had longer life span than wild type flies (Oregon) [4]; and that inhibitors of TRP-KYN metabolism, alpha-methylTRP and 5-methyl-TRP, prolonged life span of wild-type flies [5]. Inhibition of TRP-KYN metabolism exerted neuroprotective effect in flies [6]. Furthermore, inhibitors of TRP-KYN metabolism available for human use, berberine, isoquinoline alkaloid isolated from Berberis aristata, a major herb widely used in Indian and Chinese

\footnotetext{
"Corresponding author.
}

systems of medicine, is a strong inhibitor of the ratelimiting enzyme of TRP-KYN metabolism, the active ingredient of an herbal medicine $[7,13]$ and minocycline, an antibiotic with anti-inflammatory effects, prolonged life span and stimulated locomotor activity (negative geotaxis) of wild type flies [8-10].

As a continuation of our studies of berberine effect on life span we were interested to evaluate the effect of berberine of life span in flies maintained at a higher temperature $\left(28^{\circ} \mathrm{C}\right)$. It is known that life span is temperature dependent, and flies are living faster at the higher temperature [11], i.e, there is an inverse relationship between life span and temperature [12]. Our working hypothesis was that berberine protects against the aging-accelerating effect of high ambient temperature. To check this hypothesis we compared the effect of berberine on life span of 
Oregon flies kept at $23^{\circ} \mathrm{C}$ and $28^{\circ} \mathrm{C}$.

Considering that berberine is a strong inhibitor of kynurenine formation from tryptophan [13], and that genetically or pharmacologically induced deficiency of TRP conversion into KYN prolongs life span [4,5,14], we compared the effects of berberine on life span in wild type and KYN formation deficient mutants (vermilion) of Drosophila melanogaster maintained under $23^{\circ} \mathrm{C}$ and $28^{\circ} \mathrm{C}$.

\section{Methods}

Wild-type stock Oregon of Drosophila melanogaster and mutant stock vermilion from the collection of V. N. Karazin Kharkiv National University were used in the experiments. The study was carried out between June and August.

Flies were maintained at $23^{\circ} \mathrm{C}$ in a $12: 12$ light: dark period on a standard Drosophila medium consisting of sugar, yeast, agar and semolina. Berberine (Sigma Aldrich Chemical Co, USA) was added to nutrition medium in the dose of $1 \mathrm{mM}(0.4 \mathrm{mg} / \mathrm{ml}$ of nutrition medium $)$ at a larvae stage. Effective doses of berberine were selected by us in a previous investigation [7].

Flies collected in control and berberine variants were divided into two groups, one of which maintained at $23^{\circ} \mathrm{C}$ and the other at $28^{\circ} \mathrm{C}$.

Life span evaluation: one day old adult flies (males) were collected and then regularly transferred to fresh medium every 3 - 4 days. The number of dead flies was recorded at the time of transfer.

The obtained data were statistically analyzed using Wilcoxon rank-sum test and two ways ANOVA test.

\section{Results}

Effect of impaired formation of KYN on life span. Life span of vermillion male flies maintained under $23^{\circ} \mathrm{C}$ was longer (by 43\%) than life span of Oregon flies in accord with our previously published data [4] (Table 1).

Effect on high ambient temperature on life span. High ambient temperature $\left(28^{\circ} \mathrm{C}\right)$ decreased life span of Oregon flies in accordance with literature data (see above) (Figure 1). High ambient temperature decreased life span of vermillion flies as well (Figure 2). The effect of high temperature on life span was less pronounced in vermilion $(-40 \%)$ than in Oregon $(-60 \%)$ flies (Table 1$)$.

Berberine and life span of flies maintained at high temperature. Berberine attenuated the effect of exposure to $28^{\circ} \mathrm{C}$ on life span in Oregon (Figure 1) and vermilion flies (Figure 2). Berberine prolonged the life span of Oregon flies by $46 \%$ in comparison with control flies kept at $28^{\circ} \mathrm{C}$ and by $22 \%$ in vermilion flies kept at $28^{\circ} \mathrm{C}$ (Table 1).
Table 1. Life span at different temperatures and effect of berberine, in drosophila stocks.

\begin{tabular}{cccc}
\hline \multirow{2}{*}{ Stock } & \multicolumn{3}{c}{ Experimental groups } \\
\cline { 2 - 4 } & $23^{\circ} \mathrm{C}$ & $28^{\circ} \mathrm{C}$ & $28^{\circ} \mathrm{C}+$ berberine \\
\hline \multirow{2}{*}{ Oregon } & $19.94 \pm 1.24^{*}$ & $7.85 \pm 0.64$ & $11.51 \pm 1.35^{* *}$ \\
& $\mathrm{n}=168$ & $\mathrm{n}=150$ & $\mathrm{n}=98$ \\
Vermilion & $\begin{array}{c}28.52 \pm 1.65^{*} \\
\mathrm{n}=100\end{array}$ & $\begin{array}{c}17.36 \pm 0.57 \\
\mathrm{n}=94\end{array}$ & $\begin{array}{c}21.19 \pm 0.43^{\#} \\
\mathrm{n}=92\end{array}$ \\
\hline
\end{tabular}

${ }^{*}$ Mean \pm standard error; $\mathrm{n}=$ number of flies; $\mathrm{P}=0.001$ vs. $28^{\circ} \mathrm{C}$ and $28^{\circ} \mathrm{C}+$ berberine; ${ }^{* *} \mathrm{P}=0.001$ vs. $28^{\circ} \mathrm{C} ;{ }^{*} \mathrm{P}=0.001$ vs. $28^{\circ} \mathrm{C}$.

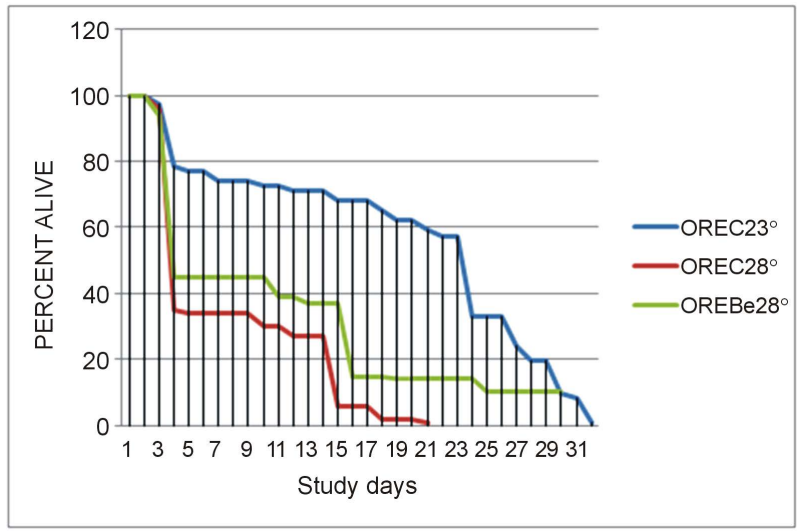

Figure 1. Berberine effect in Oregon flies. $\mathrm{OREC23}^{\circ}$ : Oregon male controls flies kept at $23^{\circ} \mathrm{C}$; OREC28 ${ }^{\circ}$ : Oregon male controls flies kept at $28^{\circ} \mathrm{C}$; $\mathrm{OREBe}^{\circ}$ : Oregon male flies kept at $28^{\circ} \mathrm{C}$ with addition of berberine.

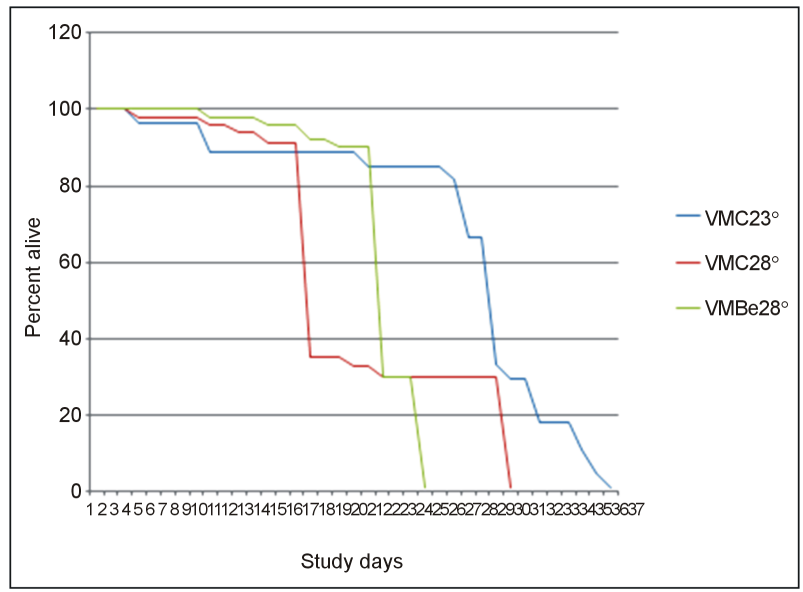

Figure 2. Berberine effect in vermilion flies. vmc23 $^{\circ}$ : vermilion male controls flies kept at $23^{\circ} \mathrm{C}$; vmc28 ${ }^{\circ}$ : vermilion male controls flies kept at $28^{\circ} \mathrm{C}$; vmBe28 ${ }^{\circ}$ : vermilion male flies kept at $28^{\circ} \mathrm{C}$ with addition of berberine.

\section{Discussion}

The main finding of our study is berberine-induced attenuation of aging-accelerating effect of high temperature in Drosophila melanogaster model. We previously reported that berberine prolonged the life span of Droso- 
phila flies kept at $23^{\circ} \mathrm{C}$ [7]. The present data indicate that berberine may enhance the ability of fruit flies to resist stress caused by high temperature, since its addition to larvae attenuated the aging-accelerating effect of high temperature. The free radical theory of aging hypothesizes that oxygen-derived free radicals are responsible for the age-related damage at the cellular and tissue levels [15], and at temperature-accelerated aging these processes might be especially intensive [11,12]. So the protective effect of berberine may be dependent on its antioxidant activity [16].

The alternative mechanism of observed protective effect of berberine against aging-accelerating action of high temperature may be related to berberine-induced inhibition of TRP-KYN metabolism. Berberine is a stronger inhibitor of TRP conversion into KYN than a "standard" inhibitor, 1-methyl-TRP [13]. Genetic and pharmacological inhibition of TRP-KYN pathway extends life span of Drosophila. Flies with mutations white (impaired transmembrane transport of TRP into cells where its metabolism occurs) and vermilion (deficiency of ratelimiting enzyme of TRP-KYN pathway, TRP 2,3-dioxygenase) had longer life spans than wild-type flies [4, 14]. Among pharmacological inhibitors of KYN formation from TRP used in our experiments were alpha-methyl-TRP and 5-methyl-TRP, berberine and minocycline, all of them prolonged the life span of wild-type Drosophila melanogaster $[5,7,8]$.

Berberine-induced attenuation of aging-accelerating effect of high temperature $\left(28^{\circ} \mathrm{C}\right)$ was less pronounced in vermilion (22\%) than in Oregon flies (46\%) (Table 1) might suggest the involvement of TRP-KYN pathway in mechanisms of high temperature effect on the life span. This suggestion might be further confirmed by less pronounced protective effect of berberine against high temperature-induced acceleration of aging in vermilion than in wild-type flies (Table 1). Present data warrant further studies of the involvement of TRP-KYN metabolism in mechanisms of high temperature-induced acceleration of aging and protective effect of berberine and other inhibitors of TRP-KYN metabolism.

The results of present and our previous studies of berberine action on life span, viability and stress-resistance of drosophila indicate that berberine is a potentially good candidate drug for anti-aging intervention and attenuation of stressful conditions impact.

\section{Acknowledgements}

GF Oxenkrug is a recipient of NIMH099517 grant.

\section{Conflict of Interest Disclosure}

Paul Summergrad is a non-promotional speaker for CME outfitters, Inc.

\section{REFERENCES}

[1] G. Oxenkrug, "Metabolic Syndrome, Age-Associated Neuroendocrine Disorders and Dysregulation of TryptophanKynurenine Pathway Metabolism," Annals of the New York Academy of Sciences, Vol. 1199, 2010, pp. 1-14.

[2] G. Oxenkrug, "Interferon-Gamma-Inducible Kynurenines/ Pteridines Inflammation Cascade: Implications for Aging and Aging-Associated Medical and Psychiatric Disorders,” Journal of Neural Transmission, Vol. 118, No. 1, 2011, pp. 75-85.

http://dx.doi.org/10.1007/s00702-010-0475-7

[3] G. Oxenkrug, "Interferon-Gamma-Inducible Inflammation: Contribution to Aging and Aging-Associated Psychiatric Disorders," Aging and Disease, Vol. 2, No. 6, 2011, pp. 474-486.

[4] G. Oxenkrug, "The Extended Life Span of Drosophila melanogaster Eye-Color (White and Vermilion) Mutants with Impaired Formation of Kynurenine," Journal of Neural Transmission, Vol. 117, No. 1, 2010, pp. 23-26. http://dx.doi.org/10.1007/s00702-009-0341-7

[5] G. Oxenkrug, V. Navrotskaya, L. Vorobyova and P. Summergrad, "Extension of Life Span of Drosophila melanogaster by the Inhibitors of Tryptophan-Kynurenine Metabolism,” Fly (Austin), Vol. 5, No. 4, 2011, pp. 307309. http://dx.doi.org/10.4161/fly.5.4.18414

[6] S. Campesan, E. W. Green, C. Breda, K. V. Sathyasaikumar, P. J. Muchowski, R. Schwarcz and C. P. Kyriacou, "The Kynurenine Pathway Modulates Neurodegeneration in a Drosophila Model of Huntington's Disease," Current Biology, Vol. 21, No. 11, pp. 961-966. http://dx.doi.org/10.1016/j.cub.2011.04.028

[7] V. V. Navrotskaya, G. Oxenkrug, L. I. Vorobyova and P. Summergrad, "Berberine Prolongs Life Span and Stimulates Locomotor Activity of Drosophila melanogaster," American Journal of Plant Sciences, Vol. 3, No. 7, 2012, pp. 1037-1040.

http://dx.doi.org/10.4236/ajps.2012.327123

[8] G. Oxenkrug, V. Navrotskaya, L. Vorobyova and P. Summergrad, "Minocycline Effect on Life and Health Span of Drosophila melanogaster," Aging and Disease, Vol. 3, No. 5, 2012, pp. 352-359.

[9] E. Bonilla, R. Contreras, E. J. Medina-Leendertz, M. Mora, V. Villalobos and Y. Bravo, "Minocycline Increases the Life Span and Motor Activity and Decreases Lipid Peroxidation in Manganese Treated Drosophila Melanogaster,” Toxicology, Vol. 294, No. 1, 2012, pp. 50-53. http://dx.doi.org/10.1016/j.tox.2012.01.016

[10] M. Mora, S. J. Medina-Leendertz, E. Bonilla, R. E. Terán, M. C. Paz and J. L. Arcaya, "Minocycline, but Not Ascorbic Acid, Increases Motor Activity and Extends the Life Span of Drosophila melanogaster," Investigación Clínica, Vol. 54, No. 2, 2013, pp. 161-170.

[11] J. Miquel, P. R. Lundgren, K. G. Bensch and H. Atlan, "Effects of Temperature on the Life Span, Vitality and Fine Structure of Drosophila melanogaster,” Mechanisms of Ageing and Development, Vol. 5, 1976, pp. 347-370. http://dx.doi.org/10.1016/0047-6374(76)90034-8

[12] E. A. Sestini, J. C. Carlson and R. Allsopp, “The Effects 
of Ambient Temperature on Life Span, Lipid Peroxidation, Superoxide Dismutase, and Phospholipase A2 Activity in Drosophila melanogaster," Experimental Gerontology, Vol. 26, No. 4, 1991, pp. 385-395. http://dx.doi.org/10.1016/0531-5565(91)90050-V

[13] C. J. Yu, M. F. Zheng, C. X. Kuang, W. D. Huang and Q. Yang, "Oren-Gedoku-To and Its Constituents with Therapeutic Potential in Alzheimer's Disease Inhibit Indoleamine 2,3-Dioxygenase Activity in Vitro," Journal of Alzheimer's Disease, Vol. 22, No. 1, 2010, pp. 257-266.

[14] M. G. Kamyshev, "Longevity and Its Relation to the Lo- comotor Activity in Tryptophan-Xanthommatin Metabolic Pathway Mutant of Drosophila," Doklady Akademii Nauk SSSR, Vol. 253, No. 5, 1980, pp. 1476-1480.

[15] D. Fusco, G. Colloca, M. R. Lo Monaco and M. Cesari, "Effects of Antioxidant Supplementation on the Aging Process,” Journal of Clinical Interventions in Aging, Vol. 2, No. 3, 2007, pp. 377-387.

[16] H. F. Ji and L. Shen, "Berberine, a Potential Multipotent Natural Product to Combat Alzheimer's Disease," Molecules, Vol. 16, No. 8, 2011, pp. 6732-6740. http://dx.doi.org/10.3390/molecules16086732 